\title{
Desarrollo de dos fórmulas infantiles como alternativa económica y saludable para seguridad alimentaria y nutricional de la población lactante
}

\author{
Development of two infant formulas as an economic and healthy alternative for help to food security and \\ nutritional security to the infant population
}

Beatriz Estella López-Marín1, Julie Maritza Álvarez-Rivera², Luz Marina Carvajal de Pabón³

1 Nutricionista Dietista, Magister en Ciencia Farmacéuticas y Alimentarias, Candidata a Doctora en Ciencia Farmacéuticas y Alimentarias. Docente investigadora Escuela de Nutrición y Dietética, integrante Grupo de Nutrición y Tecnología de Alimentos, Universidad de Antioquia. Medellín, Colombia. e-mail: beatrizestella@gmail.com

2 Ingeniera de Alimentos, Magister en Ciencias Farmacéuticas y alimentarias, Especialista de Investigación y Desarrollo. integrante Grupo de Nutrición y Tecnología de Alimentos, Universidad de Antioquia. Medellín, Colombia. e-mail: jumary20@gmail.com

3 Técnica de Laboratorio Quimico, Magister en Ciencias Agrarias. Docente pensionada Facultad de Química Farmacéutica, integrante Grupo de Nutrición y Tecnología de Alimentos, Universidad de Antioquia. e-mail: Icarvaja@gmail.com saludable para la seguridad alimentaria y nutricional de la población lactante. Univ. Salud. 2016;18(2):291-301. DOI: http://dx.doi.org/10.22267/rus.161802.39

\begin{abstract}
Resumen
Introducción: Cuando la lactancia materna no es posible, se recurre a otros alimentos que brinden los nutrientes necesarios a los bebés, como las fórmulas infantiles, con características nutricionales que cumplan con la reglamentación actual y permitan un adecuado crecimiento al lactante. Objetivo: Diseñar dos fórmulas líquidas para lactantes que aporten los requerimientos diarios de macronutrientes y algunos micronutrientes (ácido fólico, zinc, calcio y hierro), con leche de vaca, higienizada por pasteurización, de bajo costo para que sea más asequible para la población lactante vulnerable a la vez que contribuye con su crecimiento. Materiales y métodos: Estudio exploratorio desarrollado en dos fases, formulación y elaboración de los productos y verificación de su eficacia en el crecimiento de lactantes. Resultados: Los productos cumplen con los requisitos de fabricación exigidos, de bajo costo y son capaces de sustentar un crecimiento normal, según clasificación de OMS. Conclusión: Las fórmulas desarrolladas tienen un adecuado aporte de macro y micronutrientes con características sensoriales y microbiológicas bajo los criterios exigidos por la reglamentación internacional y nacional, de bajo costos, permitiendo un adecuado crecimiento al lactante.
\end{abstract}

Palabras clave: Desarrollo infantil; alimentación suplementaria; sustitutos de la leche humana; lactante; lactancia. (Fuente: DeCS, Bireme).

\begin{abstract}
Introduction: When breastfeeding is not feasible, other sources to provide the required nutrients to babies are sought, such as infant formulas that comply with current regulation and with the baby's growth requirements. Objective: To design two liquid infant formulas that provide daily macronutrients and some micronutrients (folic acid, zinc, calcium, and iron) requirements, based on low-cost pasteurized cow milk in order to be more affordable for vulnerable babies
\end{abstract}


and to contribute with their growth. Materials and Methods: Exploratory study developed in two phases: Formulation and preparation of the infant formula and verification of its efficacy in terms of babies' growth. Results: The infant formulas comply with all manufacturing requirements, are inexpensive, and appropriate to sustain normal growth, according to WHO. Conclusion: The two infant formulas developed have adequate macronutrient and micronutrient contribution with sensorial and microbiological characteristics that comply with local and foreign regulations, are inexpensive, and appropriate to sustain babies' normal growth.

Keywords: Infant development; supplemental feeding; human milk substitutes; breastfed baby; breastfeeding. (Source: DeCS, Bireme).

\section{Introducción}

La leche materna (LM) es el alimento idóneo para el bebé por sus ventajas psicológicas, afectivas, económicos, sociales, inmunológicas, protectoras (contra enfermedades crónicas no transmisibles y alergias), además facilita el desarrollo de los sistemas neurológico, inmune y gastrointestinal ${ }^{1-}$ 5. Por los efectos positivos de la LM en el lactante, la Organización Mundial de la Salud ${ }^{6}$ y la Academia Americana de Pediatría $^{2}$, la recomiendan exclusivamente hasta los seis meses y complementaria mínimo hasta el año ${ }^{7}$. No obstante, hay situaciones donde no es posible suministrarla, ejemplo: madres con cáncer, tuberculosis, VIH y depresión, insuficiente producción o por actividades relacionadas con la vida personal o profesional de la mamá8.

En la reunión de expertos sobre alimentación del lactante (OPS, OMS, \& CESNI, 1993) ${ }^{9}$, se acordó que cuando sea imposible alimentar a un bebé con LM, se deben usar sucedáneos, siendo la primera opción las fórmulas infantiles (FI) y como segunda opción leche de vaca diluida y fortificada. Sin embargo, debido al alto costo de las FI, las familias, especialmente las de bajos recursos económicos, se ven obligadas a recurrir a la leche de vaca entera (LVE) como la primera opción de alimentación, pero es de anotar que las diferencias nutricionales de la LM con la LV son elevadas y si la segunda no se modifica correctamente para que brinde al lactante todos los requerimientos nutricionales de manera adecuada, puede causar efectos adversos en el lactante; la LM por ejemplo, tiene mayor contenido de carbohidratos y grasa y menor de proteínas comparada con la LV, respecto a los micronutrientes, la LM tiene menor aporte de estos, especialmente de minerales, pero de mayor biodisponibilidad ${ }^{10}$.

En lactantes alimentados con LVE sin modificar se han reportado anemias ${ }^{8,11-13}$, sangrado intestinal ${ }^{14,15}$, deshidratación, daño renal ${ }^{16}$ y alergias ${ }^{17}$, es por esto que algunos comités relacionados con la alimentación del lactante han concluido que la LV sin modificar, no debe administrarse durante el primer año de vida ${ }^{9}$, sin embargo, también es importante informar que debido al costo de las FI, muchas familias preparan el biberón con éstas, pero de forma más diluida, situación que tampoco es favorable para el bebé debido a que él no recibe los nutrientes en la cantidad suficiente; esta situación es muy común en la población colombiana y posiblemente a nivel mundial.

Muchas familias cuyos ingresos no alcanzan para cubrir todas las necesidades de la canasta familiar dicen: para poder alimentar al bebe debemos comprar un tarro (FI) que vale entre $10 \%$ al $15 \%$ de una salario mínimo legal vigente según la marca del producto y este dura 15 días en promedio, toca hacerlo rendir mucho; este testimonio es indicativo de que la FI está siendo diluida, pues una FI preparada según recomendaciones del fabricante para que aporte todos los nutrientes al lactante dura en promedio tres días, además las madres reconocen que sus bebés tienen problemas nutricionales, por lo anterior los producto diseñado deben ser de bajo costo para que sean más asequible a las poblaciones vulnerables, permitiendo además un adecuado crecimiento del lactante sin detrimento de la salud, contribuyendo de este modo con la seguridad alimentaria y nutricional de las comunidades. 
Todo lo antepuesto describe un problema nutricional el cual debe ser tratado si deseamos disminuir el riesgo de déficit nutricional en la población infantil, por lo tanto este trabajo tuvo como objetivo diseñar y desarrollar dos fórmulas líquidas con LVE modificada, pasteurizada y de bajo costo para niños de $0-5$ meses y de 6 - 12 meses, que aporte los requerimientos diarios de macronutrientes $\mathrm{y}$ algunos micronutrientes (ácido fólico, zinc, calcio y hierro) y que a su vez, permita un adecuado crecimiento según los parámetros de la OMS y además, sea más asequibles a las poblaciones.

\section{Materiales y métodos}

El proyecto se hizo en dos fases y se tuvo en cuenta la elaboración de dos formulaciones, una para bebés de 0-5 meses y otra para bebés de 612 meses, debido a que los requerimientos nutricionales en ambos grupos varían.

\section{Fase 1: Formulación y elaboración del producto}

Inicialmente se estableció el aporte nutricional de las dos formulaciones, basados en la normatividad internacional y nacional actuales (Codex Alimentarius-Resolución 11488 de 1984), el aporte nutricional de otras FI expedidas actualmente en el mercado, además del aporte nutricional de la LM; los nutrientes que se tuvieron en cuenta fueron: proteínas, grasas, carbohidratos y algunos micronutrientes, específicamente aquellos que pudiera afectarse en su contenido por el proceso de elaboración o cuyo contenido es bajo en la LVE, como el hierro.

Materiales. LV sin higienizar, maltodextrina, aceite de canola, micronutrientes aminoquelados (hierro y zinc), lecitina de soya y monoglicéridos, las cantidades de estos materiales varían según la necesidad nutricional del lactante, las cuales dependen de la edad, entre 0 y 5 meses 29 días y mayores de 6 meses hasta 12 meses de nacidos.

Equipos. Pasteurizador, capacidad: $250 \mathrm{lt} / \mathrm{h}$, de placas, homogenizador, capacidad: $4 \mathrm{~m}^{3} / \mathrm{h}$, acumulador de hielo, capacidad: $560 \mathrm{lb}$ de hielo, caldera capacidad: 5 HP. La línea de proceso fue en sistema cerrado y el envasado se hizo de forma manual bajo las BPM (Decreto 3075/97), las muestras se almacenaron en refrigeración a $4^{\circ} \mathrm{C}$ en recipientes de dos litros de polietileno de alta densidad pigmentados.

Procedimiento. Por cada formulación (fórmula para lactantes de 0-5 meses y fórmula para lactantes de 6-12 meses) se produjeron $200 \mathrm{~L}$. Todos los ingredientes se mezclaron y posteriormente se agitaron hasta su total incorporación. La mezcla obtenida se homogenizó a una presión de 1.500 PSI, luego se pasteurizó a $75^{\circ} \mathrm{C}$ por 15 segundos y se envasó a $7{ }^{\circ} \mathrm{C}$ en garrafas de pet con capacidad de dos $\mathrm{L}$ y se conservaron en refrigeración a $4^{\circ} \mathrm{C}$.

\section{Pruebas de calidad aplicadas a los dos productos}

Pruebas microbiológicas. Se realizaron bajo la normativa colombiana, Resolución 0616 que aplica para todas las leches que se expenden en el país y la Resolución 11488/198418, que aplica alimentos destinados para lactantes.

Los métodos estuvieron basados en las Normas Técnicas Colombianas 4132, 4519, 4679, 4779 y la 451619-23. Se solicitó recuento de aerobios mesófilos, de mohos y levaduras, coliformes totales, coliformes fecales, Staphylococcus aureus coagulasa (+), Bacillus cereus y detección de Salmonella spp $/ 25 \mathrm{~g}$.

Prueba sensorial. Se realizó una prueba descriptiva, ejecutada por un panel de expertos, se trabajó con una escala de respuesta cuantitativa bajo las normas NTC 3932 y $5328^{24,25}$. Se evalúo olor y aroma característico, olor y aroma objetable, sabor característico, sabor objetable y de acuerdo a los parámetros anteriormente mencionados, se definió la calidad general. La escala de intensidad empleada fue: 0 significa "ausente",1 y 2 corresponde a "leve", 3 a "media-baja", 4 a "media", 5 a "media-alta" y finalmente $>6$ corresponde a "intensa". Según datos suministrados por el laboratorio de la fundación INTAL. 
La finalidad de la prueba fue identificar, cuales son los atributos del alimento y medir la intensidad de los mismos, además con ella se pueden identificar y describir los atributos de una muestra o muestras particulares y evaluar aceptación del producto por parte del consumidor, uno de los mayores objetivos del proyecto, incluyendo evaluación en el deterioro del mismo y su no aceptación por parte del consumidor, debido al deterioro del alimento.

Pruebas bromatológicas. Se cuantificó: proteína, grasa y carbohidratos totales, humedad, ácido fólico, hierro, calcio y zinc. Estas pruebas fueron realizadas en el laboratorio Delivery Tecnologies y los métodos empleados para ello fueron los determinados por el laboratorio (espectrofotometría, absorción atómica y HPL, según protocolos de la AOAC y adaptados).

\section{Fase 2: Verificar el efecto de las fórmulas en el crecimiento de los lactantes}

Después de formulados y elaborados los dos productos y con sus respectivas pruebas de calidad, se hizo un estudio exploratorio con siete lactantes menores de 10 meses, (tres niños y cuatro niñas), que asistían todo el día a una ONG, de lunes a viernes. Los criterios de inclusión fueron: bebés nacidos a término, sin patología graves como enfermedades cardiovascular, renales, alergias alimentarías y especialmente, alergia a la proteína de la leche, que no hubiesen presentado episodios agudos de diarrea o vómito en el último mes y que no sobrepasen la edad de 10 meses, obtener consentimiento informado por parte de los parientes del bebé, madre, padre o su cuidador. El estudio se realizó durante dos meses (tiempo en el cual se puede estimar cambios en el crecimiento), a cada lactante se le brindó la formulación según su edad (fórmula de 0-5 meses o la de 6 -12 meses).

A cada bebé se le realizaron medidas antropométricas para evaluar su crecimiento normal (peso y talla). La toma del peso se realizó con pesabebés con sensibilidad de $20 \mathrm{~g}$, la talla con infantómetro portátil de aluminio y pieza móvil para menores de dos años, con sensibilidad de $1 \mathrm{~mm}$. Cada toma antropométrica se efectuó dos veces y en caso de encontrar diferencias que superen las tolerancias establecidas (estatura dos mm y peso corporal: $300 \mathrm{~g}$ ), se ejecutó una tercera medición. La clasificación antropométrica se hizo según parámetros de la OMS. Se utilizaron las siguientes variables respuesta: peso/edad, talla/edad y peso/talla. La toma de medidas antropométricas la realizó personal con experiencia en el caso.

Los bebés fueron atendidos por nutricionista, enfermera y médico pediatra alergólogo, quién efectúo las evaluaciones médicas y determinó si el lactante podía estar en el estudio, y con disponibilidad de 24 horas para atender cualquier urgencia. Las madres recibieron indicaciones escritas sobre la forma de suministrar el producto durante los días que los niños no asistían a la ONG, con el fin de estandarizar la ingestión y garantizar que él recibiera los nutrientes necesarios. El bebé recibió un suplemento multivitamínico que le aportará los micronutrientes faltantes en la formulación.

El cumplimiento de la intervención se vigiló a partir de la valoración de la ingestión del producto por medio de una bitácora de consumo de alimentos, dónde se reportaba la cantidad de formulación o alimentos no consumidos por el lactante. La aceptabilidad fue registrada en términos del porcentaje de consumo del producto día por bebé (cantidad ofrecida día/cantidad dejada día) x 100).

Se consideró cumplimiento cuando cada participante consumió al menos el $90 \%$ de lo establecido en el plan de alimentación. Se controló la presencia de eventos adversos por entrevistas realizadas semanalmente a las madres o cuidadores del bebé, con preguntas sobre aceptación del producto, presencia de diarrea, vómito, eczema, episodios de urticaria y posible manifestación de inflamación estomacal.

Entre las consideraciones éticas se tuvo presente la Declaración de Helsinki 2008, Resolución 008430 de 1993 del Ministerio Nacional de Salud, Decreto 2378 de 2008 y la aprobación de los Comités de Ética de la Universidad de Antioquia y del Laboratorio Delivery Tecnologies. 
Después de obtenidos los productos con todas las especificaciones técnicas y pruebas de calidad se realizó su respectivo costeo. Se aplicó estadística descriptiva y las variables se describen mediante promedios, frecuencias y porcentajes. Se empleó el programa SPSS versión 20.

\section{Resultados}

Microbiológicos. Los resultados microbiológicos indican que ambas formulaciones cumplían con las especificaciones establecidas en la normativa, lo que indica que son seguros para los lactantes, sin embargo, esta debe conservarse en refrigeración, además el tratamiento térmico aplicado fue el indicado para garantizar inocuidad.

La vida de anaquel fue de 11 días, por encima del tiempo promedio de la LV pasteurizada, la cual es de siete días promedio. (Tabla 1 )

Sensorial. En la tabla 2 se muestran los resultados en términos del promedio de la intensidad de cada uno de los descriptores sensoriales, los datos reportados indican que la calidad general del producto fue alta en un $100 \%$.

Tabla 1. Resultados microbiológicos de las formulaciones lácteas

\begin{tabular}{|c|c|c|c|c|c|c|c|c|}
\hline \multirow[t]{2}{*}{ Parámetro } & \multicolumn{6}{|c|}{ Resultados (días) } & \multirow[t]{2}{*}{ Especificaciones } & \multirow[t]{2}{*}{$\begin{array}{l}\text { Método de } \\
\text { análisis }\end{array}$} \\
\hline & $\mathbf{0}$ & 2 & 6 & 11 & 20 & 23 & & \\
\hline $\begin{array}{l}\text { Recuento de } \\
\text { aerobios mesófilos } \\
\text { ufc/g }\end{array}$ & 90 & 110 & 160 & 900 & 400000 & 41000000 & 1000 & NTC 4519 \\
\hline $\begin{array}{l}\text { Recuento de } \\
\text { mohos y levaduras } \\
\text { ufc/g }\end{array}$ & $<10$ & $<10$ & $<10$ & $\begin{array}{r}<10 \mathrm{de} \\
\text { mohos } \\
11000 \mathrm{de} \\
\text { levaduras }\end{array}$ & $\begin{array}{r}<10 \mathrm{de} \\
\text { mohos } \\
2100 \mathrm{de} \\
\text { levaduras }\end{array}$ & $\begin{array}{r}<10 \mathrm{de} \\
\text { mohos } \\
13000 \mathrm{de} \\
\text { levaduras }\end{array}$ & 300 & NTC 4132 \\
\hline $\begin{array}{l}\text { NMP de } \\
\text { coliformes totales } \\
\text { NMP/g }\end{array}$ & $<3$ & $<3$ & $<3$ & $<3$ & 9 & 150 & 11 & NTC 4516 \\
\hline $\begin{array}{l}\text { NMP de } \\
\text { coliformes fecales } \\
\text { NMP/g }\end{array}$ & $<3$ & $<3$ & $<3$ & $<3$ & $<3$ & $<3$ & $<3$ & NTC 4516 \\
\hline $\begin{array}{l}\text { Recuento de } \\
\text { Staphylococcus } \\
\text { aureus coagulasa } \\
(+) \text { ufc/g }\end{array}$ & $<100$ & $<100$ & $<100$ & $<100$ & $<100$ & $<100$ & $<100$ & NTC 4779 \\
\hline $\begin{array}{l}\text { Recuento de } \\
\text { Bacillus cereus } \\
\text { ufc/g }\end{array}$ & $<100$ & $<100$ & $<100$ & $<100$ & $<100$ & $<100$ & 200 & NTC 4679 \\
\hline $\begin{array}{l}\text { Detección de } \\
\text { Salmonella } \\
\text { spp } / 25 \mathrm{~g}\end{array}$ & Ausencia & Ausencia & Ausencia & Ausencia & Ausencia & Ausencia & Ausencia & INVIMA 1998 \\
\hline $\begin{array}{l}\text { Recuento de } \\
\text { bacterias ácido } \\
\text { lácticas UFC/g }\end{array}$ & 15 & 20 & 90 & 100 & 100 & 100 & N.A & NTC 5034 \\
\hline
\end{tabular}


Tabla 2. Descriptores de calidad de la prueba sensorial de las dos formulaciones

\begin{tabular}{|c|c|c|c|}
\hline Descriptor & $\begin{array}{c}\text { Resultado } \\
\text { fórmula } \\
\text { infantil 1 }\end{array}$ & $\begin{array}{c}\text { Resultado } \\
\text { fórmula } \\
\text { infantil } 2\end{array}$ & $\begin{array}{l}\text { Referencia del } \\
\text { descriptor }\end{array}$ \\
\hline $\begin{array}{l}\text { Olor/aroma } \\
\text { característico }\end{array}$ & 7,0 & 7,0 & $\begin{array}{l}\text { Máxima } \\
\text { intensidad de } \\
\text { olor } \\
\text { característico a } \\
\text { leche }\end{array}$ \\
\hline $\begin{array}{l}\text { Olor/aroma } \\
\text { objetable }\end{array}$ & 0,0 & 0,0 & $\begin{array}{l}\text { Ausencia de } \\
\text { olor objetable }\end{array}$ \\
\hline $\begin{array}{l}\text { Sabor } \\
\text { característico }\end{array}$ & 8,50 & 8,50 & $\begin{array}{l}\text { Intenso sabor } \\
\text { característico a } \\
\text { leche }\end{array}$ \\
\hline $\begin{array}{l}\text { Sabor } \\
\text { objetable }\end{array}$ & 0,0 & 0,0 & $\begin{array}{l}\text { Ausencia de } \\
\text { sabor objetable }\end{array}$ \\
\hline $\begin{array}{l}\text { Calidad } \\
\text { general }\end{array}$ & 9,0 & 9,0 & $\begin{array}{l}\text { Máxima } \\
\text { calidad general }\end{array}$ \\
\hline $\begin{array}{l}\text { Aceptación o } \\
\text { rechazo }\end{array}$ & A & A & $\begin{array}{l}\text { El producto fue } \\
\text { aceptado por el } \\
100 \% \text { de los } \\
\text { panelistas }\end{array}$ \\
\hline Observaciones & $\begin{array}{l}\text { Leve sabor } \\
\text { a dulce }\end{array}$ & $\begin{array}{l}\text { Leve sabor } \\
\text { a dulce }\end{array}$ & \\
\hline
\end{tabular}

Los resultados sensoriales obtenidos, confirman que, tanto el proceso, como las materias primasempleadas, no tuvieron un impacto negativo en la calidad y aceptación del producto, pues la aprobación por parte del panel de evaluación fue satisfactoria en todos los parámetros evaluados. El 100\% de los panelistas calificaron las fórmulas con buena calidad general, después de valorar los descriptores de olor y sabor característicos a leche.

Bromatológicos. En ambas formulaciones por cada 100 calorías, se encontró que con respecto a los micronutrientes, la proteína y los carbohidratos cumple con el rango establecido por la Resolución 1148826, y el Codex, sin embargo la grasa se encontró en promedio $0,5 \mathrm{~g}$ por encima del valor máximo indicado por ambas normas. Con relación a los micronutrientes, el hierro está bajo los rangos establecidos por el Codex y por encima de lo establecido en la Resolución 11488/84; el calcio y zinc, se encontraron por encima del límite mínimo señalado por las dos normas, sin embargo como no hay dato sobre el valor máximo para los tres micronutrientes, estos contenidos están dando cumplimiento con lo establecido en la norma, pues si cumple en los contenidos mínimos. (Tabla $3)$.

Tabla 3. Contenido de nutrientes de las dos fórmulas lácteas diseñadas según análisis fisicoquímico*

\begin{tabular}{|c|c|c|c|c|c|c|c|c|c|}
\hline \multirow[t]{2}{*}{$\begin{array}{c}\text { Componente } \\
\text { nutricional }\end{array}$} & \multirow[t]{2}{*}{$\begin{array}{l}\text { Unidad de } \\
\text { medida }\end{array}$} & \multirow{2}{*}{$\begin{array}{c}\text { Valor } \\
\text { laboratorio } \\
\text { F }^{* *} \\
0-5 \\
\text { meses }\end{array}$} & \multirow{2}{*}{$\begin{array}{l}\text { Valor } \\
\text { teórico } \\
\text { F 0-5 } \\
\text { meses }\end{array}$} & \multirow{2}{*}{$\begin{array}{c}\text { Valor } \\
\text { laboratorio } \\
\text { F 6-12 } \\
\text { meses }\end{array}$} & \multirow{2}{*}{$\begin{array}{l}\text { Valor } \\
\text { teórico } \\
\text { F 6-12 } \\
\text { meses }\end{array}$} & \multicolumn{2}{|c|}{ CODEX } & \multicolumn{2}{|c|}{$\begin{array}{c}\text { Resolución } \\
\text { 11488/84 }\end{array}$} \\
\hline & & & & & & Min & Max & Min & Max \\
\hline Proteína & g/100 calorías & 3,0 & 3,0 & 3,0 & 3,4 & 1,8 & 3,0 & 1,8 & 4,0 \\
\hline Grasa & g/100 calorías & 6,8 & 6,0 & 7,0 & 6,0 & 4,4 & 6,6 & 3,3 & 6,0 \\
\hline Carbohidratos & g/100 calorías & 10,7 & 12 & 10,7 & 12 & 9,0 & 14,0 & $\mathrm{NE}^{* * *}$ & $\mathrm{NE}$ \\
\hline Calcio & mg/100 calorías & 147 & 100 & 147 & 100 & 50 & -- & 50 & -- \\
\hline Hierro & mg/100calorias & 1,0 & 1,0 & 1,0 & 1,0 & 0,45 & -- & 1 & -- \\
\hline Zinc & $\mathrm{mg} / 100$ calorias & 2,0 & 0,5 & 2,0 & 0,5 & 0,5 & -- & 0,5 & -- \\
\hline
\end{tabular}

**F: Fórmula, ${ }^{* * * N E}$ : no especificado

* Reporte del laboratorio en 100 calorías de producto comparado con el teórico y con las exigencias de las actuales regulaciones (internacional y nacional) por cada 100 calorías. 
Antropométricos. Los siete lactantes mostraron crecimiento constante, continuando su patrón de crecimiento (peso y talla) igual a cuando ingresaron al estudio, según clasificación de la OMS. La tabla 4 reporta la evolución del peso y la talla del niño en cada toma, mostrando un aumento de estos con vías a lograr una talla y un peso adecuado para la edad durante el tiempo que recibieron el tratamiento, la tabla 5 muestra la clasificación del estado nutricional según la $\mathrm{OMS}^{27}$.

Tabla 4. Reporte de la evaluación antropométrica de participantes

\begin{tabular}{|c|c|c|c|c|c|c|c|c|c|c|c|c|}
\hline Participantes & $\begin{array}{l}\text { Edad en meses / } \\
\text { días al inicio del } \\
\text { tratamiento }\end{array}$ & $\begin{array}{l}\text { Edad en meses / } \\
\text { días al final del } \\
\text { tratamiento }\end{array}$ & $\begin{array}{c}\text { Peso } \\
1 \mathrm{~K}\end{array}$ & $\begin{array}{l}\text { Talla } \\
1 \mathrm{~cm}\end{array}$ & $\begin{array}{c}\text { Peso } \\
2 \mathrm{k}\end{array}$ & $\begin{array}{l}\text { Talla } \\
2 \mathrm{~cm}\end{array}$ & $\begin{array}{c}\text { Peso } \\
3 \mathrm{k}\end{array}$ & $\begin{array}{l}\text { Talla } \\
3 \mathrm{~cm}\end{array}$ & $\begin{array}{c}\text { Peso } \\
4 \mathrm{k}\end{array}$ & $\begin{array}{l}\text { Talla } \\
4 \mathrm{~cm}\end{array}$ & $\begin{array}{c}\text { Peso } \\
5 \mathrm{k}\end{array}$ & $\begin{array}{l}\text { Talla } \\
5 \mathrm{~cm}\end{array}$ \\
\hline \multicolumn{13}{|c|}{ Población de 0 a 5 meses } \\
\hline 001 & 5 meses - 2 días & 7 meses - 1 día & 7,4 & 63,4 & 7,8 & 63,5 & 8,1 & 65,5 & 8,2 & 65,5 & 8,4 & 66,5 \\
\hline 002 & 2 meses - 6 días & 4 meses - 5 días & 3,5 & 53 & 4,3 & 55,1 & 5,8 & 57,7 & 6,4 & 60 & 7 & 62 \\
\hline \multicolumn{13}{|c|}{ Población de 6 a 12 meses } \\
\hline 003 & 6 meses -26 días & 8 meses- 25 días & 6,6 & 67 & 6,9 & 68,5 & 7,3 & 70,3 & 7,4 & 71 & 7,4 & 71,2 \\
\hline 004 & 9 meses - 19 días & 11 meses- 20 días & 6,8 & 69 & 7 & 69,3 & 7,5 & 70 & 7,6 & 71,1 & 7,8 & 72,5 \\
\hline 005 & 9 meses-25 días & 12 meses- 26días & 7,9 & 70,5 & 8,1 & 71,2 & 8,2 & 71,9 & 8,2 & 73,4 & 8,4 & 73,9 \\
\hline 006 & 9 meses - 3 días & 11 meses- 4 días & 6,1 & 67,3 & 6,5 & 65,4 & $\mathrm{SD}^{*}$ & SD & 6,6 & 66,1 & 6,8 & 66,3 \\
\hline 007 & 9 meses- 24 días & 11 meses-24 días & 9,7 & 71 & 9,4 & 71,1 & 9,7 & 71,7 & 9,8 & 72,2 & 10 & 73,1 \\
\hline
\end{tabular}

*SD: sin dato

Tabla 5. Distribución porcentual de la clasificación antropométrica de los participantes según la OMS

\begin{tabular}{|c|c|c|c|c|c|c|c|c|c|c|c|}
\hline \multicolumn{4}{|c|}{ Clasificación P/T } & \multicolumn{4}{|c|}{ Clasificación T/E } & \multicolumn{4}{|c|}{ Clasificación P/E } \\
\hline Toma & Clasificación & $\mathrm{n}$ & $\%$ & Toma & Clasificación & $\mathrm{n}$ & $\%$ & Toma & Clasificación & $\mathrm{n}$ & $\%$ \\
\hline \multirow{6}{*}{1} & Delgadez severa & 0 & 0,0 & \multirow{6}{*}{1} & Baja talla severa & 0 & 0,0 & \multirow{6}{*}{1} & Peso bajo severo & 1 & 14,3 \\
\hline & Delgadez & 1 & 14,3 & & Baja talla & 2 & 28,6 & & Peso bajo & 2 & 28,6 \\
\hline & Normal & 6 & 85,7 & & Normal & 5 & 71,4 & & Normal & 4 & 57,1 \\
\hline & Sobrepeso & 0 & 0,0 & & Total & 7 & 100,0 & & Exceso de peso & 0 & 0,0 \\
\hline & Obesidad & 0 & 0,0 & & & & & & Total & 7 & 100,0 \\
\hline & Total & 7 & 100,0 & & & & & & & & \\
\hline \multirow{6}{*}{2} & Delgadez severa & 0 & 0,0 & \multirow{6}{*}{2} & Baja talla severa & 0 & 0,0 & \multirow{6}{*}{2} & Peso bajo severo & 0 & 0,0 \\
\hline & Delgadez & 0 & 0,0 & & Baja talla & 1 & 14,3 & & Peso bajo & 2 & 28,6 \\
\hline & Normal & 7 & 100,0 & & Normal & 6 & 85,7 & & Normal & 5 & 71,4 \\
\hline & Sobrepeso & 0 & 0,0 & & Total & 7 & 100,0 & & Exceso de peso & 0 & 0,0 \\
\hline & Obesidad & 0 & 0,0 & & & & & & Total & 7 & 100,0 \\
\hline & Total & 7 & 100,0 & & & & & & & & \\
\hline
\end{tabular}




\begin{tabular}{|c|c|c|c|c|c|c|c|c|c|c|c|}
\hline & Delgadez severa & 0 & 0,0 & \multirow{6}{*}{3} & Baja talla severa & 0 & 0,0 & \multirow{6}{*}{3} & Peso bajo severo & 0 & 0,0 \\
\hline \multirow{5}{*}{3} & Delgadez & 0 & 0,0 & & Baja talla & 0 & 0,0 & & Peso bajo & 0 & 0,0 \\
\hline & Normal & 6 & 100,0 & & Normal & 6 & 100,0 & & Normal & 6 & 100,0 \\
\hline & Sobrepeso & 0 & 0,0 & & Total & 6 & 100,0 & & Exceso de peso & 0 & 0,0 \\
\hline & Obesidad & 0 & 0,0 & & & & & & Total & 6 & 100,0 \\
\hline & Total & 6 & 100,0 & & & & & & & & \\
\hline \multirow{6}{*}{4} & Delgadez severa & 0 & 0,0 & \multirow{6}{*}{4} & Baja talla severa & 0 & 0,0 & \multirow{6}{*}{4} & Peso bajo severo & 0 & 0,0 \\
\hline & Delgadez & 0 & 0,0 & & Baja talla & 1 & 14,3 & & Peso bajo & 1 & 14,3 \\
\hline & Normal & 7 & 100,0 & & Normal & 6 & 85,7 & & Normal & 6 & 85,7 \\
\hline & Sobrepeso & 0 & 0,0 & & Total & 7 & 100,0 & & Exceso de peso & 0 & 0,0 \\
\hline & Obesidad & 0 & 0,0 & & & & & & Total & 7 & 100,0 \\
\hline & Total & 7 & 100,0 & & & & & & & & \\
\hline \multirow{6}{*}{5} & Delgadez severa & 0 & 0,0 & \multirow{6}{*}{5} & Baja talla severa & 0 & 0,0 & \multirow{6}{*}{5} & Peso bajo severo & 0 & 0,0 \\
\hline & Delgadez & 0 & 0,0 & & Baja talla & 1 & 14,3 & & Peso bajo & 1 & 14,3 \\
\hline & Normal & 7 & 100,0 & & Normal & 6 & 85,7 & & Normal & 6 & 85,7 \\
\hline & Sobrepeso & 0 & 0,0 & & Total & 7 & 100,0 & & Exceso de peso & 0 & 0,0 \\
\hline & Obesidad & 0 & 0,0 & & & & & & Total & 7 & 100,0 \\
\hline & Total & 7 & 100,0 & & & & & & & & \\
\hline
\end{tabular}

P/T: peso para la talla. T/E: talla para la edad. P/E: peso para la edad

\section{Discusión}

El desarrollo de alimentos para lactantes está reglamentado por la normatividad internacional y nacional, la cual busca que estos brinden los nutrientes necesarios para su adecuado desarrollo y crecimiento, la prevención de deficiencias nutricionales y posiblemente un mejor desarrollo de las funciones inmunológicas 28 , por tal razón los productos alimenticios diseñados en este proyecto cumplen con la reglamentación internacional y nacional en lo que respecta al contenido nutricional de los macronutrientes y de los micronutrientes en mención (hierro, calcio, zinc).

Con respecto al contenido de carbohidratos, ambas formulaciones cumple con las cantidades reglamentadas y aunque el $100 \%$ de estos no es a base de lactosa como el de la LM, esta complementado con dextrinomaltosa, esta combinación tiene efectos favorables en el lactante, pues el contenido de lactosa proveniente de la LV permite al lactante continuar recibiendo los efectos benéficos de ésta (efecto bactericida, mejor absorción de minerales y aporte de galactooligosacáridos que son componentes fundamentales para el desarrollo neurológico del lactante ${ }^{29} \mathrm{y}$ con el aporte de la dextrinomaltosa se obtiene un leve sabor dulce y es complemento al resto de carbohidratos faltantes, a la vez que se evita que este se adapten a sabores muy dulces desde edades muy tempranas, situación que se presentaría, si se hubiese empleado sacarosa como carbohidrato complementario ${ }^{30}$.

Es importante traer a consideración que durante el primer año de vida, las grasas proveen gran parte del requerimiento energético/día del lactante (del 40 al 50\%), permitiendo que el bebé tenga un adecuado respaldo calórico para su crecimiento significativo, aumento de peso que se da en esta etapa según recomendaciones de la ESPGHAN; los alimentos para lactantes deben garantizar una absorción de lípidos mínimo de un $85 \%$, ésta se ve favorecida cuanto menos grasas saturadas haya ${ }^{28}$. La grasa de las fórmulas infantiles diseñadas provienen de la propia grasa de la LV, además fueron enriquecidas con aceite de canola, por lo tanto tienen un buen contenido de ácidos grasos poli insaturados, comparados con los saturados, esta condición es un factor 
favorecedor para su absorción, suministrando de esta manera una buena cantidad de lípidos al lactante.

Un exceso de proteína para el lactante, puede causar sobrecarga renal y posiblemente obesidad y sobrepeso infantili1 ${ }^{31}$, por tal razón una fórmula infantil debe contener la cantidad de proteína suficiente y necesaria para cubrir los requerimientos del lactante, permitiéndole un correcto crecimiento y desarrollo, por esta razón las fórmulas infantiles diseñadas en este proyecto, contienen la cantidad de proteína adecuada para la edad del bebé según la normatividad internacional y nacional, evitando recarga renal o posible sobrepeso u obesidad, a la vez que favorece el correcto crecimiento, además la proteína brindada es de alto valor biológico, pues provienen de la LV.

La LM como la LV son pobres en hierro, aunque la biodisponibilidad es mayor en la primera $(70 \%$ frente al $30 \%$ en la $L V)^{28}$, sin embargo es de conocimiento general que en los hábitos alimentarios de los lactantes, predomina el consumo de leche, sin embargo, los niños nacidos a término y cuya alimentación hasta los seis meses es exclusivamente con LM, no presentan esta deficiencia, ya que el hierro es más bioaccesible y biodisponible a pesar de su baja concentración, pero en lactantes cuyo alimento base es LV sin modificar pueden presentar mayor riesgo de padecer anemia ferropénica y por ende disminución en la actividad física y en la actividad motriz espontánea ${ }^{32}$, inadecuado funcionamiento de algunas enzimas involucradas en el funcionamiento del sistema nervioso central, problemas en el desarrollo mental, motor y conductual, principalmente durante el crecimiento 33 .

Lactantes que desarrollan una anemia leve por deficiencia de hierro, presentan un desarrollo psicomotor significativamente menor en comparación con los lactantes que no han tenido deficiencia ${ }^{32}$, lactantes que presentan anemia severa, muestran ciertas alteraciones en las funciones conductuales y socio-emocionales ${ }^{34}$.
Bajo este conocimiento las dos fórmulas diseñadas se fortificaron con hierro, exactamente para prevenir situaciones de anemia y problemas de salud en los bebés. Las fórmulas infantiles diseñadas fueron fortificadas con hierro amino quelado reportando unos contenidos de $1 \mathrm{mg} / 100$ calorías según normatividad internacional (Codex Stand 72 ) y por encima de los valores mínimos exigidos por la normatividad nacional (Resolución 11488/84), lo que evita la anemia ferropénica por baja ingesta de hierro en este grupo de edad.

El zinc y el calcio son minerales que deben ser aportado en la alimentación diaria del lactante, por ende deben ser suministrados en el alimento base de su dieta como lo es la fórmula infantil, en las cantidades suficientes que cubran los requerimientos nutricionales, especialmente en estos primeros meses de nacido. Una fórmula infantil debe aportar como mínimo por cada 100 calorías 0,5 mg de zinc y $50 \mathrm{mg}$ de calcio, según lo establecido por los expertos en alimentación infantil (EPSGHAN-CODEX).

Los productos diseñados cumplen con estos requerimientos ya que el aporte reportado de estos micronutrientes en cada formulación supera los mínimos requeridos, pero además, estos micronutrientes pueden tener una mejor biodisponibilidad debido a que el calcio proviene de la LV reporta una absorción en promedio del $40 \% 35$, aunque no es igual al de la LM, si es mayor al compararse con algunos compuestos de calcio empleados para fortificar alimentos ${ }^{36}$. El zinc y el hierro empleados para la fortificación fueron aminoquelados cuya absorción es mayor, puesto que se encuentra unido al ácido etilendiaminotetraacético (EDTA), esta estructura ha mostrado tener una elevada absorción, incluso cuando el alimento fortificado tiene un elevado contenido de inhibidores ${ }^{37}$.

De acuerdo con la normatividad internacional y nacional, las leches infantiles deben ser productos inocuo, en este estudio se demostró que los productos obtenidos lo son, pues los análisis microbiológicos mostraron cumplimiento de la normatividad exigida, además una mayor durabilidad en el tiempo comparado con la leche 
pasteurizada, sin embargo su manejo higiénico domiciliario debe ser estricto, pues una inadecuada manipulación es causal de contaminación y posible enfermedad en el lactante, igual como ocurriría con otra FI en polvo, si esta no se manipula de manera higiénica.

Con respecto a la eficiencia del producto en el crecimiento de los lactantes, se observa que ellos no desmejoraron en ningún momento su estado nutricional, según clasificación por la OMS, sin embargo es de anotar que el aumento de peso estuvo constante en la mayoría de los casos, igualmente la talla, posiblemente alcanzando niveles más cercanos a la mediana según la clasificación de la OMS 27 , a pesar de que esta población de lactantes no presentan todas las condiciones óptimas para su adecuado desarrollo como una alimentación complementaria ajustada, adecuado ambiente familiar, condiciones higiénica y servicios de salud entre otras, aun así después de suministrarles el producto se puede observar una mejora o mantenimiento en sus indicadores antropométricos.

Al costearse el producto se obtuvo que un litro de este tiene un costo promedio a un litro de leche, sin ninguna modificación nutricional, higienizada para comercializar, por consiguiente este producto es asequible a las poblaciones vulnerables, cuyos ingresos son bajos, además puede ser incluido en los programas gubernamentales que tienen como objetivo la nutrición de sus comunidades.

Finalmente, es pertinente decir que es posible lograr una FI a base de LV modificada que sustente un adecuado crecimiento en los lactantes y que pueda ser más asequible a nuestra población, igualmente este producto lo pueden hacer otras comunidades, donde los problemas de desnutrición para esta población tan vulnerable los aqueja enormemente y cuya solución es relativamente fácil y poco compleja.

El trabajo permite concluir que se desarrollaron dos fórmulas para lactantes listas para el consumo, con un adecuado aporte nutricional a partir de leche vaca modificada y otros ingredientes, con características sensoriales y microbiológicas óptimas, que permiten un adecuado crecimiento y pueden ser consideradas una alternativa de alimentación de bajo costo para los lactantes, cuyas familias no puedan suplir su alimentación con FI en polvo.

Agradecimientos: Los autores expresan su agradecimiento a la empresa Inversiones $\mathrm{Mi}$ Vaquita.

Conflicto de intereses: Pueden presentarse conflictos de interés con la presente investigación, con asociaciones que defienden la leche materna como único alimento lácteo para el bebé hasta los 12 meses de nacidos y no ven ninguna probabilidad de que muchas madres no pueden lactar debido a situaciones particulares descritas con anterioridad en este artículo.

\section{Referencias}

1. Macías S, Rodríguez S, Ronayne P. Leche materna: composición y factores condicionantes de la lactancia. Arch argent pediatr. 2006:104(5):423-430

2. The American Academy of Pediatrics. Breast feeding and the use of human milk. Pediatrics. 2012;129(3):e827e841.

3. Díaz T, Soler Q. Aspectos epidemiológicos relacionados con la lactancia materna durante el primer año de vida. Rev. Cubana Med Gen Integr. 2013;18(3):183-186.

4. Mota C, Herrero V, Yep C, García G, Sánchez B. Asociación entre alergia e intolerancia a proteínas de leche de vaca y enterocolitis hemorrágica en el primer mes de vida. Bol Pediatr. 2011;51:165-168.

5. Terrero E, Álvarez J, Novás J, Ferrer M. Lactancia materna y su relación con el exceso de peso corporal en adolescentes de secundaria básica. Revista Cubana de Medicina General Integral. 2010;26(1):14-25.

6. WHO. Global strategy for infant and young child feeding. Geneva, 2001. Disponible en: http://apps.who.int/gb/archive/pdf_files/WHA54/ea5 4id4.pdf

7. Krawinkel M. Benefits from longer breastfeeding: do we need to revise the recommendations? Curr Probl Pediatr Adolesc Health Care. 2011; 41:240-243.

8. López B, Martínez L, Zapata N. Motivos para el abandono temprano de la lactancia materna, un problema de salud ppública no resuelto en la ciudad de Medellín. Revista de salud pública. 2013;13(5):1-10.

9. OPS, OMS, CESNI. La alimentación del niño menor de seis años en América Latina. Bases para el desarrollo de guías de alimentación. Informe reunión-taller. Islas Margarita, 1993.

10. Bowman B, Russell R. Conocimientos actuales sobre nutrición (8 ed.) PAHO: Washington; 2009. 
11. Posada A, Gómez F, Ramírez H. El Niño Sano (3 ed.). Editorial Médica Panamericana. 2005.

12. Segura A, Maestre C, Cure C. [Internet] Influencia de la lactancia materna exclusiva o alimentación temprana con fórmula sobre las enfermedades durante la niñez. 2002. [Consultado agosto de 2014]. Disponible en: http://www.encolombia.com/medicina/revistasmedicas/alergia/vol-112/alergia11202lactanciamaterna/

13. Yimyaen $\mathrm{P}$, Vivatvakin $\mathrm{B}$, Chongsrisawat $\mathrm{V}$, Wisedopas $\mathrm{N}$. Gastrointestinal manifestation of cow's milk protein allergy during the first years of life. Medical Association of Thailand. 2003;86(2):116-123.

14. Correa J, Gómez J, Posada R. Fundamentos de Pediatría (3 ed). Medellín: Fondo Editorial CIB; 2006.

15. Díaz-Argüelles Ramírez-Corría VM. La alimentación inadecuada del lactante sano y sus consecuencias. Rev Cubana Pediatr [Internet]. 2005 Mar [citado 2016 Abr 12] ; 77(1):. Disponible en: http://scielo.sld.cu/scielo.php?script=sci_arttext\&pid= S0034-75312005000100007\&lng=es.

16. Guillén-López S, Vela-Amieva M. Desventajas de la introducción de la leche de vaca en el primer año de vida. Acta Pediatr Mex.2010; 31(3):123-128.

17. Orsi M, Fernández A, Marchisone S, Busoni V. Proposed guidelines for the management of children with cow's milk protein allergy. Arch Argent Pediatr. 2009;107(5): 459-470.

18. Alcaldía de Bogotá D.C, Secretaría General. Decreto 616 de 2006. Santa Fé de Bogotá: Alcaldía; 2006.

19. Colombia. Icontec. NTC 4132. Microbiología. Guía general para el recuento de mohos y levaduras. Técnica de recuento de colonias a $25^{\circ} \mathrm{C} .1997$.

20. Colombia. Icontec. NTC 4519. Microbiología de los alimentos para consumo humano y animal. Método horizontal para el recuento de microorganismos. Técnica de recuento de colonias a $30^{\circ} \mathrm{c} .1998$.

21. Colombia. Icontec. NTC 4679. Microbiología. Método horizontal para el recuento de Bacillus Cereus. Técnica de recuento de colonias. 2006.

22. Colombia. Icontec. NTC 4779. Microbiología de alimentos y alimentos para animales. Método horizontal para el recuento de Estafilococos coagulasa positiva (Staphylococcus aureus y otras especies). 2007.

23. Colombia. Icontec. NTC 4516. Microbiología de alimentos y productos de alimentación animal. Método horizontal para la detección y enumeración de coliformes técnica del número más probable. 2009.

24. Colombia. Icontec. NTC 3932. Análisis sensorial. Identificación y selección de descriptores para establecer un perfil sensorial por una aproximación multidimensional. 1996.

25. Colombia. Icontec. NTC 5328. Análisis sensorial. Directrices para el uso de escalas de respuesta cuantitativas. 2004.

26. República de Colombia. Resolución 11488 de 1984, por la cual se dictan normas en lo referente a procesamiento, composición, requisitos y comercialización de los alimentos infantiles, de los alimentos o bebidas enriquecidos y de los alimentos o bebidas de uso dietético. Bogotá, 1984.
27. WHO. Multicentre Growth Reference Study Group. WHO Child Growth Standards: Length/height-for-age, weightfor-age, weight-for-length, weight-for-height and body mass index-for-age: Methods and development. Geneva: World Health Organization; 2006.

28. García M. Lactancia artificial. Pediatría Integral. 2011; XV(4):331-343.

29. Fondo de las Naciones Unidas para la Infancia, 1995. [Internet]. La leche humana, composición, beneficios y comparación con la leche de vaca. Disponible en: http://www.unicef.cl/lactancia/docs/mod01/Mod\%20 1beneficios\%20manual.pdf

30. Villares J, Leal L, Segovia M. [Internet]. Cómo enriquecer la alimentación del lactante: uso de los módulos nutricionales. Disponible en: http://www.gastroinf.es/sites/default/files/files/Secci Nutri/COMO.pdf

31. Koletzko B, Kries R, Closa R. Lower protein in infant formula is associated with lower weight up to age $2 \mathrm{y}$ : a randomized clinical trial. Am J Clin Nutr. 2009; 89(6):1836-1845.

32. Haas J, Brownlie T. Iron deficiency and reduced work capacity: a critical review of the research to determine a causal relationship. J Nutr. 2001;131:676S-688S.

33. Angulo-Kinzler R, Peirano P, Lozoff B. Spontaneous motor activity in human infants with iron-deficiency anemia. EarlyHum Dev. 2002;66:67-79.

34. Lozoff B, Beard J, Connor J, Felt B, Georgieff M, Schallert T. Longlasting neural and behavioral effects of iron deficiency in infancy. Nutr Rev. 2006;64:34-43.

35. Rodríguez F. Estudio del metabolismo mineral y enzima antioxidante durante la evolución de una anemia ferropénica nutricional. Tesis Doctoral. Granada: Universidad de Granada. Facultad de Farmacia, Departamento de Fisiología, Instituto de Nutrición y Tecnología de Alimentos José Mataix; 2011.

36. Valencia G, Román M, Cardona S. El calcio en el desarrollo de alimentos funcionales. Revista Lasallista de Investigación. 2011;8(1):104-116.

37. Haro V. Biodisponibilidad de diferentes compuestos de hierro añadidos a un néctar de frutas funcional. Interacción con las vitaminas y fructooligosacáridos. Tesis Doctoral. Murcia: Universidad de Murcia. Facultad de Veterinaria y Ciencia y Tecnología de los Alimentos; 2006. 